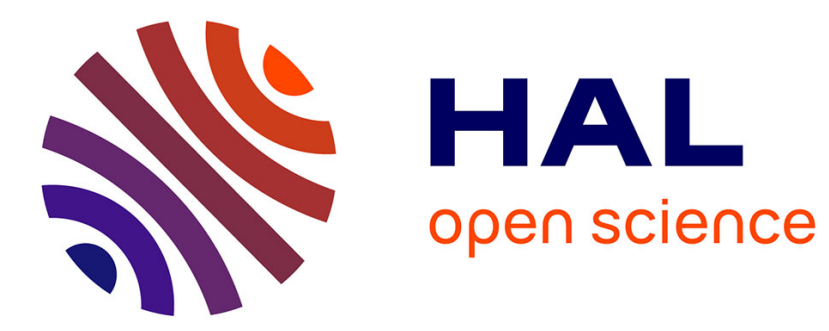

\title{
Direct Synthesis of Polysubstituted Aluminoisoxazoles and Pyrazoles by a Metalative Cyclization
}

Olivier Jackowski, Thomas Lecourt, Laurent Micouin

\section{To cite this version:}

Olivier Jackowski, Thomas Lecourt, Laurent Micouin. Direct Synthesis of Polysubstituted Aluminoisoxazoles and Pyrazoles by a Metalative Cyclization. Organic Letters, 2011, 13 (20), pp.5664-5667. $10.1021 /$ ol202389u . hal-02185376

\section{HAL Id: hal-02185376 https://hal.science/hal-02185376}

Submitted on 17 Jul 2019

HAL is a multi-disciplinary open access archive for the deposit and dissemination of scientific research documents, whether they are published or not. The documents may come from teaching and research institutions in France or abroad, or from public or private research centers.
L'archive ouverte pluridisciplinaire HAL, est destinée au dépôt et à la diffusion de documents scientifiques de niveau recherche, publiés ou non, émanant des établissements d'enseignement et de recherche français ou étrangers, des laboratoires publics ou privés. 


\title{
Direct Synthesis of polysubstituted \\ aluminoisoxazoles and pyrazoles by a Metalative Cyclization.
}

\author{
Olivier Jackowski, Thomas Lecourt, Laurent Micouin* \\ UMR8638, CNRS-Paris Descartes University, Faculté de Pharmacie, 4 av. de \\ l'Observatoire, 75006 Paris, France.
}

Laurent.micouin@parisdescartes.fr

Received Date (will be automatically inserted after manuscript is accepted)

\section{ABSTRACT}
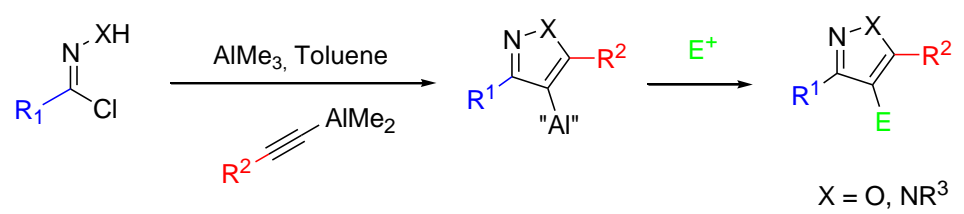

Alumino-heteroles are obtained from simple precursors in a fully chemo and regio-selective manner by a metalative cyclization. The carbon-aluminum bond is still able to react further with several electrophiles, without the need of transmetalation. This synthetic route provides a novel entry to heterocyclic organoaluminum reagents as well as a straightforward access to $3,4,5$ trisubstituted isoxazoles and 1,3,4,5 tetrasubstituted pyrazoles.

The preparation of main-group aryl and heteroaryl organometallics is a very active field, as these reagents are key intermediates in diversity-oriented elaboration of compounds for pharmaceutical and material science applications. ${ }^{1}$ In this context, the preparation of aryl- or heterocyclic organoaluminum reagents has gained a renewed interest, due to their potential broad functional tolerance, ${ }^{2}$ and the low cost and toxicity of alanes. ${ }^{3}$

A conventional preparative method for aromatic organoaluminum compounds has been the transmetalation of the corresponding lithium or magnesium derivatives with various aluminum(III) sources, ${ }^{4}$ or in some cases trough aluminum-tin or boron exchange reactions. ${ }^{5}$ However, the transmetalation pathway, generally conducted at low temperature from reactive organolithium reagents, ${ }^{6}$ generates salts as side products. These salts have been reported to strongly affect the reactivity ${ }^{7}$ of the final organoaluminum reagent and the enantioselectivity of asymmetric processes. ${ }^{8}$ This procedure is very often conducted in ethereal solvents, known to strongly decrease the Lewis acidity of organoaluminum reagents, and therefore to affect their reactivity. Finally, the potential functional group tolerance of the carbon- aluminum bond cannot be exploited if organoaluminum reagents are prepared from the corresponding lithiated or magnesiated derivatives. ${ }^{9}$

More recently, several alternative procedures, based on directed metalation ${ }^{10}$ or oxidative insertion ${ }^{2}$ have been reported, leading to functionalized aromatic organoaluminum compounds. However, in most cases, these organometallic reagents must be transmetalated before further reaction. New alternative routes to aluminated heterocycles is therefore desirable.

In our on-going work in the field of organoaluminum chemistry, ${ }^{11}$ we have reported the preparation of functional aluminotriazoles by a copper catalysed cycloaddition of organic azides and mixed aluminium acetylides. ${ }^{12}$ Herein, we report that aluminated heteroles can be prepared by a tandem addition/intramolecular 5 endo-dig metalative cyclization mechanism (Figure 1). This kind of cyclization is well precedented for transitionmetal catalysed synthesis of various heterocycles ${ }^{13}$ and it has been shown that a stoichiometric amount of metalated precursor can lead to metalated benzoheteroles in an efficient manner. ${ }^{14}$ However, despite these examples, such 
a pathway has never been used to prepare aluminated heterocycles.

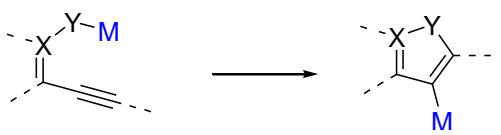

Figure 1. General principle of metalated heterocycles synthesis by a metalative cyclization process

We first turned our attention on aluminated isoxazoles synthesis. Isoxazole is indeed a privileged structure encountered in numerous compounds with biological activities, natural products and functional materials. ${ }^{15}$ Furthermore, acces to these structures from alkynyloxime using catalytic ${ }^{16}$ or stoichiometric electrophilic activation $^{17}$ is well documented.

Scheme 1. Metalative cyclisation of oxime 1
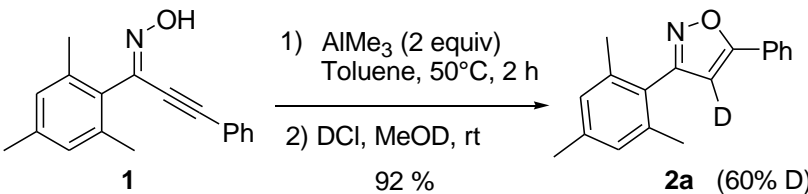

2a $(60 \% D)$

Cyclization product 2a was indeed obtained in $92 \%$ yield, starting from compound $\mathbf{1}$ in the presence of 2 equivalents of trimethylaluminum. However, only partial $(60 \%)$ deuterium incorporation was observed. This modest deuterium incorporation can be explained by a competitive in situ protonation of the aluminated intermediate. ${ }^{18}$ In order to avoid this troublesome sidereaction, we decided to generate the metallated precursor directly from nitrile oxide 3. Although nitrile oxides are not considered as electrophiles, complexation to aluminum reagents could increase their electrophilicity and decrease their dipole reactivity, as already noticed by Kanemasa and co-workers. ${ }^{19}$ To our delight, 93\% deuterated isoxazole $\mathbf{2 a}$ was obtained with 2 equivalents of dimethyl-phenylalkynylaluminum ${ }^{20}$ and mesitylene carbonitrile oxide, after deuterolysis of the reaction mixture (Table 1, entry 1 ). The use of only one equivalent of aluminium acetylide led to the formation of alkynyl oxime 1 as major reaction product (entry 2), showing that external electrophilic assistance is required to triger the cyclization. Thus, addition of one equivalent of $\mathrm{AlMe}_{3}$ after initial reaction between nitrile oxide and aluminum acetylide resulted in the clean formation of compound $\mathbf{2 a}$ in $76 \%$ isolated yield (Table 1, entry 3 ). Interrestingly, even a substoichiometric amount of $\mathrm{AlMe}_{3}$ can assist the reaction, although $20 \%$ are needed to achieve a correct conversion (entry 4).
Table 1. Optimization of the reaction conditions

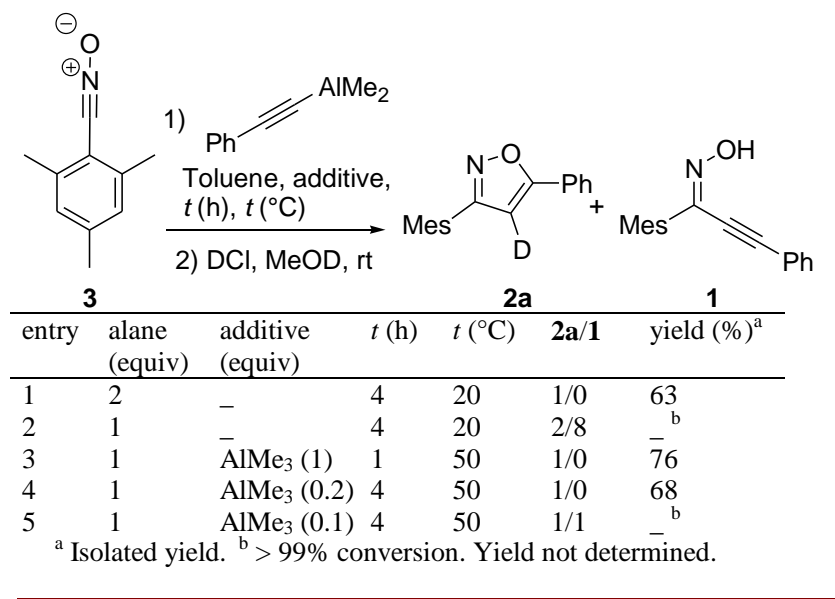

All these experiments support a tandem addition/intramolecular 5 endo-dig metalative cyclization mechanism (Scheme 2). ${ }^{21}$ Although the role of aluminium $\pi$-acidity is well known in carbo- and hydroalumination reactions, and several examples have been reported showing that aluminum derivatives can trigger a trans addition on a triple bond, ${ }^{22}$ this intramolecular transhydroxyalumination is, to the best of our knowledge, unprecedented.

Scheme 2. Proposed mechanistic pathway

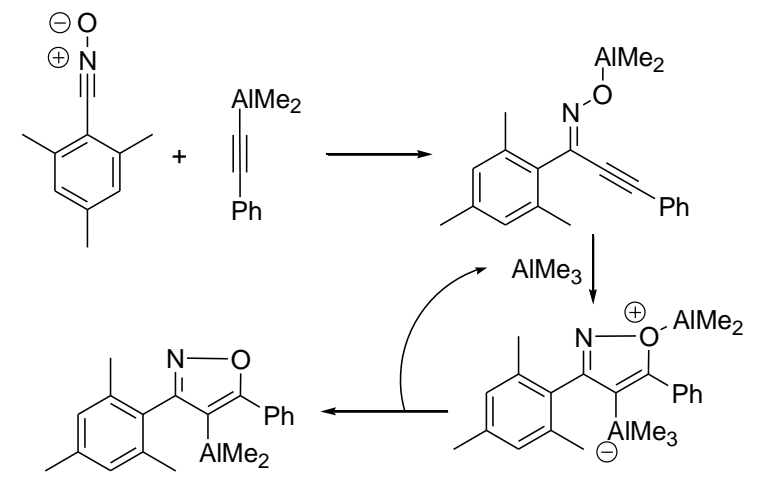

Optimized experimental conditions were then applied to a variety of dimethylaluminum alkynides bearing aromatic, alkyl, chloroalkyl and alkenyl groups (Table 2). In all the cases, the 3,5-disubstitued 4-metalated isoxazoles were obtained as unique regioisomers, with more than $94 \%$ deuterium incorporation at the mechanistically expected 4 position after deuterolysis. 
Table 2. Scope of the reaction: alkyne

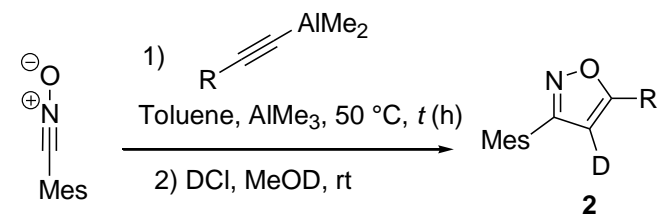

\begin{tabular}{llllll}
\hline entry & $\mathrm{R}$ & $\begin{array}{l}\mathrm{AlMe}_{3} \\
\text { (equiv) }\end{array}$ & $t(\mathrm{~h})$ & compound & yield $(\%)^{\mathrm{a}}$ \\
\hline 1 & $\mathrm{Ph}$ & 1 & 1 & $\mathbf{2 a}$ & 76 \\
2 & $\mathrm{Ph}$ & 0.2 & 4 & $\mathbf{2 a}$ & 68 \\
3 & $\mathrm{nPr}$ & 1 & 1.5 & $\mathbf{2 b}$ & 69 \\
4 & $\mathrm{nPr}$ & 0.2 & 4 & $\mathbf{2 b}$ & 64 \\
5 & $\mathrm{Cl}\left(\mathrm{CH}_{2}\right)_{3}$ & 1 & 1.5 & $\mathbf{2 c}$ & 73 \\
6 & $\mathrm{Cl}\left(\mathrm{CH}_{2}\right)_{3}$ & 0.2 & 4 & $\mathbf{2 c}$ & 61 \\
7 & & 1 & 1.5 & $\mathbf{2 d}$ & 71 \\
8 & & 0.2 & 4 & $\mathbf{2 d}$ & 60
\end{tabular}

${ }^{\text {a }}$ Isolated yield

Variation of the nitrile-oxide part was then investigated. As unhindered nitrile-oxides are notoriously unstable, ${ }^{23}$ the formation of aluminated isoxazoles was attempted starting from aromatic (Table 3, entries 1-4) or aliphatic (Table 3, entry 5) hydroximoyl chlorides. Best results were obtained using one equivalent of trimethylaluminum, followed by one equivalent of mixed acetylides, leading to the clean formation of several metalated isoxazoles. Interestingly, non only aromatic, but also aliphatic- substituted isoxazoles can be obtained in a fully regioselective manner (Table 3 , entry 5 ).

Table 3. Scope of the reaction: oxime

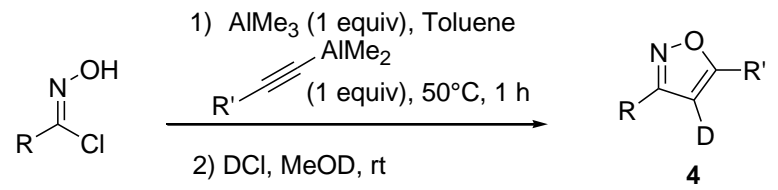

\begin{tabular}{lllll}
\hline entry & $\mathrm{R}$ & $\mathrm{R}^{\prime}$ & compound & yield $(\%)^{\mathrm{a}}$ \\
\hline 1 & $4-\mathrm{Cl}-\mathrm{Ph}$ & $\mathrm{Ph}$ & $\mathbf{4 a}$ & 70 \\
2 & $4-\mathrm{Cl}-\mathrm{Ph}$ & $\mathrm{nPr}$ & $\mathbf{4 b}$ & 68 \\
3 & $4-\mathrm{MeO}-\mathrm{Ph}$ & $\mathrm{nPr}$ & $\mathbf{4 c}$ & 53 \\
4 & $\mathrm{Ph}$ & $\mathrm{nPr}$ & $\mathbf{4 d}$ & 73 \\
5 & $\mathrm{Ph}\left(\mathrm{CH}_{2}\right)_{2}$ & $\mathrm{nPr}$ & $\mathbf{4 e}$ & 74
\end{tabular}

${ }^{\mathrm{a}}$ Isolated yield

The reactivity of these new aluminated heterocycles was explored (Scheme 3). Thus, compounds $\mathbf{5 a}$ and $\mathbf{5 b}$ could be obtained by reaction with several $N$-halosuccinimides. Once again, mesitylene carbonitrile oxide proved to be a valuable electrophile, leading to compound 5c in $65 \%$ yield. Introduction of a primary amide functional group could also be realized using a reagent recently proposed by Knochel for the functionalization of organozinc halides. ${ }^{24}$ Although aryl and/or heteroaryl organoaluminum species are generally transmetallated before further reaction, these two last examples clearly show that a C-C bound formation from aluminated isoxazoles can be performed without the help of any other metal source.

Scheme 3. Reactivity of aluminated isoazoles ${ }^{\mathrm{a}}$
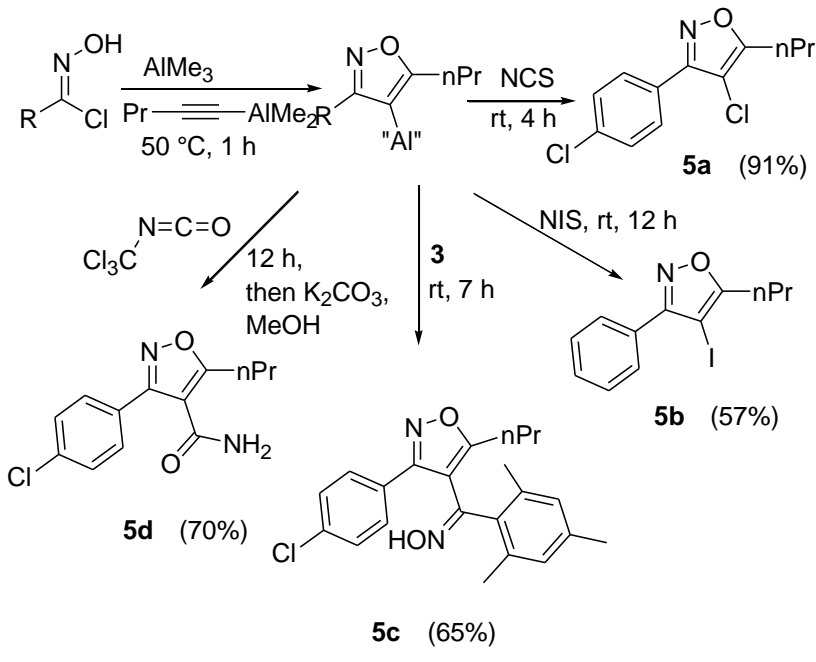

Thus, this regioselective one-pot 3 components reaction is, to our opinion, a valuable alternative to the direct cycloaddition of nitrile oxides with internal alkynes. This reaction indeed generally suffers from low yield and regioselectivity unless appropriate alkynes, nitrile-oxide precursors and/or subtle kinetically controlled reaction conditions are chosen. ${ }^{25}$

Finally, extension of this metalative cyclization reaction to the synthesis of aluminated pyrazoles starting from compound 6 was briefly investigated (Table 4). After experimental conditions optimisation, we found that an additional amount of 0.5 equiv of trimethylaluminum was necessary to achieve good conversion into the metalated pyrazole. Thus, deuterated pyrazole $(91 \%$ D) 7 a was obtained in $75 \%$ yield as a single regioisomer (Table 4 , entry 1) . Chlorination using N-chlorosuccinimide (NCS) enabled the preparation of chlorinated compounds $7 \mathbf{b}-\mathbf{e}$ (Table 4, entries 2-5), showing that aluminated trisubstituted pyrazoles can also be prepared using a metalative cyclisation reaction. 
Table 4. Extension to the synthesis of aluminated pyrazoles

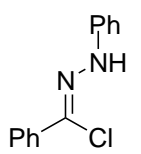

6
1) $\mathrm{AlMe}_{3}$ (1 equiv), Toluene

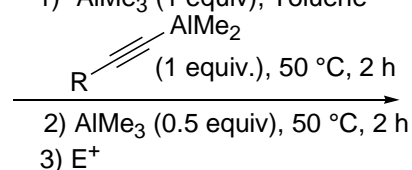

3) $E^{+}$

\begin{tabular}{llllll}
\hline entry & $\mathrm{R}$ & $\mathrm{E}^{+}$ & $\mathrm{E}$ & compound & yield $(\%)^{\mathrm{a}}$ \\
\hline 1 & $\mathrm{nPr}$ & $\mathrm{DCl}, \mathrm{MeOD}$ & $\mathrm{D}$ & $\mathbf{7 a}$ & 75 \\
2 & $\mathrm{nPr}$ & $\mathrm{NCS}$ & $\mathrm{Cl}$ & $\mathbf{7 b}$ & 89 \\
3 & $\mathrm{Cl}\left(\mathrm{CH}_{2}\right)_{3}$ & $\mathrm{NCS}$ & $\mathrm{Cl}$ & $\mathbf{7 c}$ & 84 \\
4 & $\mathrm{Ph}$ & $\mathrm{NCS}$ & $\mathrm{Cl}$ & $\mathbf{7 d}$ & 79 \\
5 & & $\mathrm{NCS}$ & $\mathrm{Cl}$ & $\mathbf{7 e}$ & 71 \\
& & & & &
\end{tabular}

In conclusion, we have developed an access to polysubstituted alumino-heteroles, based on a metalative cyclization. The regioselectivity of this reaction, combined with the reactivity of the final organoaluminum compounds, enables a rapid and simple access to $3,4,5-$ trisubstituted isoxazoles with three points of variation introduced in the same operation. We have also shown that this reaction can be extended to the preparation of the corresponding 1,3,5-trisubstituted 4-aluminopyrazoles. More generally, this synthetic pathway provides an alternative entry to complex heterocyclic organoaluminum reagents, with unexplored reactivity. We expect the present strategy to be applicable to other heterocyclic systems.

Acknowledgment Financial support from ANR (ANR blanc AluMeth) is acknowledged

Supporting Information Available Experimental procedures and characterization of compounds 2a-d, 4a-e, 5a-d, 7a-e. This material is available free of charge via the Internet at http://pubs.acs.org.

(1) (a) Handbook of Functionnalized Organometallics (Ed. P. Knochel), WILEY-VCH, Weinheim, 2005. (b) Chinchilla, R.; Najera, C.; Yus, M. Chem. Rev. 2004, 104, 2667.

(2) Blümke, T.; Chen, Y.-H.; Peng, Z.; Knochel, P. Nature Chem. $2010,2,313$.

(3) Although organoaluminum reagents are usually regarded as hazardous reagents, their pyrophoric character is mainly a problem with low-molecular weight reagents, such as trimethylaluminum, and is drastically reduced when working with diluted solutions in hydrocarbons. The non-pyrophoric limits for trimethylaluminum are $11 \mathrm{wt} \%$ in hexane and $14 \mathrm{wt} \%$ in heptane : (a) Suzuki, K.; Nagasawa, T. In Encyclopaedia of Reagents for Organic Synthesis; Paquette L. A., Ed., John Wiley \&Sons Ltd: Chichester, 1995; Vol. 7, 5186. Thus, commercially available $2 \mathrm{M}$ solution of trimethylaluminum in heptane can be handled like a commercially available MeLi or BuLi solution. This is confirmed by comparable safety data sheets hazards identification according to EC regulations between these reagents. In this work, we only used commercially available $2 \mathrm{M}$ solutions of trimethylaluminum. For a discussion on this problem, see also: Von Zezschwitz, P. Synthesis, 2008, 1809.
(4) (a) Eisch, J. J. In Comprehensive Organometallic Chemistry, Wilkinson, G; Stone, F. G. A.; Abel, E. W., Eds., Pergamon: Oxford, 1982; Vol. 1, 555. (b) Ishikawa, T.; Ogawa, A.; Hirao, T. J. Am. Chem. Soc. 1998, 120, 5124. (c) Hawner, C. ; Li, K.; Cirriez, V.; Alexakis, A. Angew. Chem. Int. Ed. 2008, 47, 8211.

(5) (a) Eisch, J. J.; Mackenzie, K.. Windisch, H.; Krüger, C. Eur. J. Inorg. Chem. 1999, 153. (b) Tschinkl, M.; Bachmann, R. E.; Gabbaï, F. P.; Chem. Commun. 1999, 1367. (c) Bochmann, M.; Sarfield, M. J. Organometallics 1998, 17, 4684.

(6) Gao, F.; Lee, Y.; Mandai, K.; Hoveyda, A. H. Angew. Chem. Int. Ed. 2010, 49, 8370 .

(7) (a) Westerman, J.; Imbery, U.; Nguyen, A. T.; Nickisch, K. Eur. J. Inorg. Chem. 1998, 295. (b) Kawamura, S.; Ishizuka, K.; Takaya, H.; Nakamura, M. Chem. Commun. 2010, 46, 6054.

(8) (a) Müller, D.; Hawner, C.; Tissot, M.; Palais, L.; Alexakis, A Synlett 2010, 1694. (b) Hawner, C.; Müller, D.; Gremaud, L.. Felouat, A.. Woodward, S.; Alexakis, A. Angew. Chem. Int. Ed. 2010, 49, 7769.

(9) The good fonctional group tolerance of trimethylaluminum is for instance used in many copper-catalyzed asymetric transformations, or trimethyl-aluminum assisted transformation, were $\mathrm{AlMe}_{3}$ acts as a non reactive methyl donor and/or Lewis acid.

(10) (a) Naka, H.; Masanobu, M.; Matsumoto, Y.; Wheatley, A. E. H.; McPartlin, M.; Morey, J. V.; Kondo, Y. J. Am. Chem. Soc. 2007, 129, 1921. (b) Mulvey, R. E.; Mongin, F.; Uchiyama, M.; Kondo, Y. Angew. Chem. Int. Ed. 2007, 46, 3802. (c) Wunderlich, S. H.; Knochel P. Angew. Chem. Int. Ed. 2009, 48, 1501. (d) Kienle, M.; Unsinn, A.; Knochel, P. Angew. Chem. Int. Ed. 2010, 49, 4751.

(11) (a) Feuvrie, C.; Blanchet, J.; Bonin, M.; Micouin, L. Org. Lett 2004, 6, 2333. (b) Wang, B.; Bonin, M.; Micouin, L. Org. Lett. 2004, 6, 3481. (c) Wang, B.; Bonin, M.; Micouin, L. J. Org. Chem. 2005, 70, 6126.

(12) Zhou, Y.; Lecourt, T.; Micouin, L. Angew. Chem. Int. Ed. 2010, 49, 2607.

(13) Nakamura, I.; Yamamoto, Y. Chem. Rev. 2004, 104, 2127

(14) (a) Nakamura, M.; Ilies, L.; Otsubo, S.; Nakamura, E. Angew. Chem. Int. Ed. 2006, 45, 944. (b) Nakamura, M.; Ilies, L.; Nakamura, E. Org. Lett. 2006, 8, 2803. (c) Tsuji, H.; Sato, K.; Ilies, L.; Itoh, Y.; Sato, Y.; Nakamura, E. Org. Lett. 2008, 10, 2263. (d) Ilies, L.; Tsuji, H.; Nakamura, E. Org. Lett. 2009, 11, 3966. (e) Yin, Y.; Ma, W.; Chai, Z.; Zhao G. J. Org. Chem. 2007, 72, 5731. (f) Yin, Y.; Chai, Z.; Ma, W.-Y.; Zhao, G. Synthesis 2008, 4036.

(15) Sutharchanadevi, M.; Murugan, R. In Comprehensive Heteterocyclic Chemistry, Katritzky, A. R.; Ress, C. W.; Scriven, E. F. V. Eds, Elsevier, 1996, Vol. 3, 221.

(16) (a) Praveen, C.; Kalyanasundaram A.; Perumal P. T. Synlett 2010, 777. (b) Ueda, M.; Sato, A.; Ikeda, Y.; Miyoshi, T.; Naito, T.; Miyata, O. Org. Lett. 2010, 12, 2594. (c) Murarka, S.; Studer, A. Org. Lett. 2011, 13, 2746.

(17) (a) Waldo, J. P.; Larock, R. C. Org. Lett. 2005, 7, 5203. (b) Waldo, J. P.; Mehta, S.; Neuenswander B.; Lushington G. H.; Larock, R. C. J. Comb. Chem. 2008, 10, 658.

(18) A similar competitive protonation has been observed in a related metalative cyclization: see ref. $14 \mathrm{~b}$.

(19) Kanemasa, S.; Kobayashi, S.; Nishiuchi, M.; Yamamoto, H.; Wada, E. Tetrahedron Lett. 1991, 32, 6367.

(20) Zhou, Y.; Lecourt, T.; Micouin, L Adv. Synth. Catal. 2009, 351, 2595.

(21) NMR monitoring of the reaction with mesitylene carbonitrile oxide clearly demonstrated the absence of any protonated species before quenching with deuterium chloride. We also have checked that no alumination of protonated isoxazole can occur under the reaction conditions. The isolation of intermediate 1 rules out a concerted mechanism involving a transient metalacycle, as proposed for coppercatalyzed synthesis of isoxazoles: Himo, F.; Lovell, T.; Hilgraf, R.; Rostovtsev, V. V.; Noodleman, L.; Sharpless, K. B.; Fokin, V. V. J. Am. Chem. Soc. 2005, 127, 210.

(22) Intermolecular reactions: (a) Asao, N.; Yoshikawa, E.; Yamamoto, Y. J. Org. Chem. 1996, 61, 4874. Intramolecular reactions: (b) Asao, N.; Sudo, T.; Yamamoto, Y. J. Org. Chem. 1996, 61, 7654

(23) Grundmann, C.; Dean, J. M. J. Org. Chem. 1965, 30, 2809.

(24) Schade, M. A.; Manolikakes, G.; Knochel, P. Org. Lett. 2010, 12,3648 .

(25) (a) Grecian, S.; Fokin, V. V. Angew. Chem. Int. Ed. 2008, 47, 8285. (b) Moore, J. E.; Davies, M. W.; Goodenough, K. M.; Wybrow, R. A. J.; York, M.; Johnson, C. N.; Harrity, J. P. A. Tetrahedron 2005 , 61, 6707. (c) Crossley, J. A.; Browne, D. L. J. Org. Chem. 2010, 75, 5414 . 